\title{
EFFECT OF HIGH INTENSITY INTERVAL TRAINING ON VO2MAX OF SEDENTARY STUDENTS
}

\author{
Retsianing Tyas Oktalia Siyyi, Mei Kusumaningtyas \\ Study Program in Physiotherapy, School of Health Polytechnic, \\ Ministry of Health Surakarta
}

\begin{abstract}
Background: VO2max refers to the maximum amount of oxygen an individual can utilize during exercise. It is commonly used to test the aerobic endurance or cardiovascular fitness of athletes before and at the end of a training cycle. VO2max is measured in milliliters of oxygen consumed in one minute, per kilogram of body weight $(\mathrm{mL} / \mathrm{kg} / \mathrm{min})$. This study aimed to determine the effect of High-Intensity Interval Training (HIIT) on VO2max in sedentary students.

Subjects and methods: This was a randomized controlled trial (RCT) conducted at the School of Health Polytechnic Surakarta, Central Java, from November to December 2020. A random sample of 30 students was randomly assigned into 2 groups: (1) group undertaking High-Intensity Interval Training (HIIT) and (2) group not undertaking HIIT. The dependent variable was VO2max measured by McArdle Step Test. The independent variable was High-Intensity Interval Training. The HIIT was carried out for 4 weeks with a frequency of 3 times a week. The mean difference of VO2max between the HIIT group and the none HIIT group after intervention was tested by independent t-test.

Results: The mean VO2max in the HIIT group (Mean $=35 ; \mathrm{SD}=2.40 \mathrm{~mL} / \mathrm{kg} / \mathrm{min}$ ) was higher than that in the group without HIIT (Mean $=32 ; \mathrm{SD}=1.95 \mathrm{~mL} / \mathrm{kg} / \mathrm{min}$ ), and it was statistically significant $(\mathrm{p}=0.027)$.

Conclusion: High-Intensity Interval Training is effective in increasing VO2max in sedentary students.

Keywords: High-Intensity Interval Training, vo2max, sedentary, students

\section{Correspondence:}

Retsianing Tyas Oktalia Siyyi. Study Program in Physiotherapy, School of Health Polytechnic, Ministry of Health Surakarta. Jl. Adi Sumarmo, Tohudan, Colomadu, Surakarta, central Java. Email: oktaliasiyyi@gmail.com. Mobile phone: +6287832287828
\end{abstract}

